\title{
KORELASI TINGKAT KEBUGARAN JASMANI DENGAN KECERDASAN LINGUISTIK SISWA KELAS TINGGI
}

\author{
Cecep $^{1)}$, Rahmat Permana ${ }^{2}$, Meiliana Nurfitriani ${ }^{3}$. \\ ${ }^{1}$ Fakultas Keguruan dan Ilmu Pendidikan, Universitas Muhammadiyah Tasikmalaya \\ email: ecepday@gmail.com \\ ${ }^{2}$ Fakultas Keguruan dan Ilmu Pendidikan, Universitas Muhammadiyah Tasikmalaya \\ email: rahmat.pgsd@umtas.ac.id \\ ${ }^{3}$ Fakultas Keguruan dan Ilmu Pendidikan, Universitas Muhammadiyah Tasikmalaya \\ email: meiliana.nurfitriani@umtas.ac.id
}

\begin{tabular}{l}
\hline Artikel Info \\
\hline Koresponden penulis : \\
Nama: Cecep \\
Email: ecepday@gmail.com \\
\\
$\square$ Diterima 8 Juli 2020 \\
$\square$ Direview 30 Oktober 2020 \\
$\square$ Disetujui 31 Oktober 2020 \\
$\square$ Dipublikasi 31Oktober 2020
\end{tabular}

Kata Kunci:

Kebugaran Jasmani; Kecerdasan Linguistik

\begin{abstract}
Abstrak
Kebugaran jasmani merupakan suatu kemampuan seseorang untuk melaksanakan aktivitas sehari-hari tanpa mengarami kelelahan yang berarti, Sekolah SD Negeri 2 Cimanggu merupakan salah satu sekolah Negeri yang belum mempunyai gambaran umum tingkat kebugaran jasmani dan juga tingkat kecerdasan linguistik khususnya pada kelas tinggi. Maka dari itu peneliti tertarik untuk mengkorelasikan tingkat kebugaran jasmani dengan kecerdasan linguistik dan apabila terdapat korelasi positif dan signifikan akan menjadi perhatian setiap guru supaya berperan dalam menjaga tingkat kebugaran jasmani siswanya. Metode penelitian yang digunakan yaitu metode korelasional yaitu mencari hubungan antar dua variabel atau lebih. Penelitian ini dilaksanakan di SD Negeri 2 Cimanggu Kecamatan Puspahiang Kabupaten Tasikmalaya pada siswa kelas tinggi saja dengan berjumlah 61 siswa. Teknik analisis data yang dilakukan pada penelitian ini adalah analisis data kuantitatif dan untuk Teknik pengumpulan data menggunakan tes dan angket. Hasil dari penelitian korelasi tingkat kebugaran jasmani dengan kecerdasan linguistik siswa kelast tinggi SD Negeri 2 Cimanggu dengan jumlah sampel $(n)=61$ dengan taraf signifikansi 5\%. Nilai koefisien bernilai sebesar 0,773. Koefisien ini bernilai searah menunjukan hubungan yang searah, artinya apabila tingkat kebugaran jasmani baik maka tingkat kecerdasan linguistik siswa juga baik.
\end{abstract}

Keywords:

Physical Fitness; Linguistic ntelligence

\begin{abstract}
Physical fitness is a person's ability to carry out daily activities without experiencing significant exhaustion, Cimanggu Public Elementary School 2 is one of the public schools that does not yet have a general picture of physical fitness and linguistic intelligence levels especially in high classes. Therefore researchers are interested in correlating the level of physical fitness with linguistic intelligence and if there is a positive and significant correlation it will be the concern of every teacher to play a role in maintaining the physical fitness level of their students. The research method used is the correlational method that is looking for relationships between two or more variables. This research was conducted at SD Negeri 2 Cimanggu, Puspahiang Subdistrict, Tasikmalaya Regency, with only 61 high school students. The data analysis technique used in this study is quantitative data analysis and for data collection techniques using tests and questionnaires. The results of the study correlated the level of physical fitness with the linguistic intelligence of high kelast students at SD Negeri 2 Cimanggu with the number of samples $(n)=61$ with a significance level of 5\%. The coefficient value is 0.773 . This coefficient has a direct value indicating a direct relationship, meaning that if the level of physical fitness is good, the level of students' linguistic intelligence is also good.
\end{abstract}




\section{PENDAhUluan}

Pada saat ini, terdapat kecenderungan meningkatnya jumlah anak dan remaja yang kurang aktif secara fisik, melihat sekarang perkembangan era digital yang kian melesat dan menyebabkan permainan anak atau remaja yang tadinya aktif menggerakan organ tubuh sekarang terbalik permainan itu terdapat di gadget yang menyebabkan kurangnya gerak tubuh. Maka kemungkinan besar kebugaran jasmani menurun disebabkan kurangnya gerak organ tubuh maka kemungkinan kesehatan juga menurun sehingga nikmatnya makan, minum, tidur, serta kemampuan bergerak, bekerja dan berfikir, akan berkurang atau hilang dengan terganggunya kesehatan. Oleh karena itu, senantiasa kita harus menjaga agar kebugaran jasmani baik. Menurut Tarigan (2009: 28-29), bahwa "Kebugaran jasmani adalah kesanggupan untuk melakukan kegiatan sehari-hari dengan semangat penuh kesadaran, yang dilakukan tanpa mengalami kelelahan yang berarti, serta dapat terhindar dari penyakit kurang gerak (hyipokenetic) sehingga dapat menikmati kehidupan yang baik dan bersahaja." Maka ketika kebugaran jasmani baik kesehatan pun terjaga sehingga melakukan aktifitas dengan penuh semangat kesadaran begitupun di jenjang pendidikan akan terasa manfaatnya terhadap konsentrasi otak yang mengatur kepada seluruh tubuh.

Dalam perkembangan terdapat berbagai aspek seperti perkembangan kognitif, afektif dan psikomotor. Maka ketika kebugaran jasmani baik maka tingkat perkembangan baik misalkan pengetahuan dan pemahaman dalam pendidikan juga akan lebih optimal, begitupun dengan kesehatan akan baik pula seperti yang dikemukakan oleh Neiman (dalam Nur, 2016: 37) menjelaskan bahwa "elemen-elemen kebugaran jasmani yang dapat diukur terbagi menjadi dua kelompok, yaitu kebugaran yang berhubungan dengan kemampuan dan kebugaran yang berhubungan dengan kesehatan." Pada penelitian Carison et al (2008) menunjukan bahwa pendidikan jasmani tidak berdampak negatif terhadap prestasi akademik siswa, bahkan pada siswa perempuan terdapat peningkatan nilai matematika dan membaca pada siswa yang mendapat pendidikan jasmani yang lebih banyak. Hasil riset memperlihatkan bahwa ketika memiliki kebugaran jasmani baik maka terhadap prestasi belajar atau nilai akademik pun terjadi peningkatan, seperti yang dikemukakan pada penelitian (Podulka et al, 2006) Mekanisme bagaimana siswa dapat meningkatkan prestasi akademik sebagai hasil dari aktivitas fisik melalui pendidikan jasmani diantaranya adalah meningkatnya motivasi dan berkurangnya rasa bosan, yang pada akhirnya dapat meningkatkan rentang perhatian dan konsentrasi.

Penelitian (Caterino, 1999) dalam Blaydes (2001) menyimpulkan bahwa fokus mental dan tingkat konsentrasi siswa meningkat secara bermakna sesudah aktivitas fisik yang terstruktur. Beberapa Hasil riset penelitian yang terdapat bahwa tingkat kebugaran jasmani berperan pada fungsi kognitif khususnya di tingkat pendidikan sekolah dasar agar tercapainya tujuan pembelajaran yang optimal. 


\begin{tabular}{|c|c|c|}
\hline Unipa Sunalaga & $\begin{array}{l}\text { Journal STAND: Sports and Development } \\
\text { http://jurnal.unipasby.ac.id/index.php/stand/about/submissions } \\
\text { jurnal.stand@unipasby.ac.id }\end{array}$ & $\Xi 7$ \\
\hline
\end{tabular}

Dalam pendidikan juga khususnya di tingkat sekolah dasar terdapat kompetensi bahasa yang harus dimiliki oleh siswa yaitu keterampilan menyimak, berbicara, membaca, menulis serta kemampuan dalam berkomunikasi secara jelas dan santun. Kompetensi-kompetensi itu berkaitan dengan kecerdasan siswa dalam berbahasa yang disebut kecerdasan linguistik. Berdasarkan teori Gardner (2003: 23) kecerdasan linguistik merupakan salah satu unsur dari kecerdasan majemuk. Dalam kegiatan sehari-hari kecerdasan linguistik sangat berpengaruh karena berkaitan dengan bahasa atau alat komunikasi dalam kehidupan sehari-hari. Begitupun di tingkat satuan pendidikan sekolah dasar bahasa merupakan dasar yang harus dimiliki karena berkaitan dengan menyimak, menulis, membaca, menghafal dan berbahasa yang baik ketika berkomunikasi. Menurut Rochman (dalam Rahmawati 2016: 229) kecerdasan linguistik adalah kemampuan akal peserta didik untuk menggunakan katakata secara efektif, baik secara lisan maupun dalam bentuk tulisan. sehingga kecerdasan linguistik menjadi hal yang sangat penting khususnya di tingkat pendidikan dasar. Kecerdasan bahasa memiliki ciri kemampuan mengekspresikan pikiran secara verbal, mudah mengingat nama atau sesuatu, dan mampu menulis dengan baik, dan biasanya anak tersebut banyak mengajukan pertanyaan dan senang berdiskusi, Wahyu (dalam Umaroh, 2013: 66). Peserta didik yang memiliki tingkat kecerdasan linguistik maka akan mampu mengingat atau menghafal dengan baik dengan konsentrasi yang baik pula karena kebugaran tubuh dan kesehatan sehingga memiliki semangat dalam pelaksanaan pembelajaran yang diharapkan.

Tingkat satuan pendidikan dasar khususnya Sekolah Dasar Negeri 2 Cimanggu dalam pendidikan jasmani belum pernah melakukan dan belum mengetahui gambaran umum tentang tingkat kebugaran jasmani peserta didik dan belum mengetahui juga gambaran umum tentang kecerdasan linguistik pada peserta didik sehingga kurangnya perhatian pada tingkat kebugaran jasmani maka peneliti tertarik dalam melakukan penelitian pada hubungan kebugaran jasmani dengan kecerdasan linguistik. Menurut Podulka (2006) kondisi aerobik tampaknya membantu fungsi memori, aktivitas fisik mempunyai pengaruh pada lobus frontalis, suatu area otak untuk konsentrasi mental dan perencanaan. Sehingga dalam penelitian ini dapat mengetahui pengukuran kebugaran jasmani dan kecerdasan linguistik. Sehingga seberapa besar korelasi kebugaran jasmani baik dengan kecerdasan linguistik dan seberapa besar korelasi kebugaran jasmani rendah dengan kecerdasan linguistik. Maka ini menjadi suatu bahan perhatian guru dalam memperhatikan tingkat kebugaran jasmani peserta didik supaya diperhatikan dalam kebugaran jasmani peserta didik agar membantu fungsi memori dalam otak terhadap 
http://jurnal.unipasby.ac.id/index.php/stand/about/submissions jurnal.stand@unipasby.ac.id

aktivitas belajar maupun tingkat kecerdasan peserta didik di SD Negeri 2 Cimanggu.

\section{METODE PENELITIAN}

Jenis penelitian ini adalah penelitian korelasional dengan menggunakan pendekatan kuantitatif. Menurut Menurut Gay (dalam Sukardi, 2008: 185) penelitian korelasional merupakan salah satu bagian penelitian expostfacto karena biasanya peneliti tidak memanipulasi keadaan variabel yang ada dan langsung mencari keberadaan hubungan dan tingkat hubungan variabel yang direflesikan dalam koefisien korelasi. Dalam artian penelitian korelasi mencari keberadaan hubungan antara variabel.

Dalam penelitian ini menggunakan sampel sebanyak 61 yakni dari kelas tinggi SD Negeri 2 Cimanggu yaitu dari kelas 4-6. Pengambilan sampel dalam penelitian ini menggunakan tes dan kuesioner, untuk tes dilakukan pada tes kebugaran jasmani menggunakan beep test dan untuk kecerdasan linguistik menggunakan kuesioner yang didalamnya meliputi aspek menulis, membaca, menyimak dan berbahasa yang baik.

Pelaksanaan untuk pengambilan data dilakukan sebanyak dua kali, pertama untuk pengambilan tes kebugaran jasmani menggunakan beep test yakni siswa lari bolakbalik mengikuti irama beep sampai siswa tidak mampu mengikuti irama beep tersebut maka itu tingkat kebugaran jasmani siswa pada aspek daya tahannya. Pengambilan data kedua yaitu menggunakan kuesioner untuk mengetahui kecerdasan linguistik siswa. Analisis data menggunakan program aplikasi pengolah data SPSS versi 15.0 dengan uji normalitas dan linieritas serta uji korelasi.

\section{HASIL DAN PEMBAHASAN}

Penelitian ini dilakukan di SD Negeri 2 Cimanggu Kecamatan Puspahiang. Pada penelitian ini peneliti mengambil subjek dari kelas tinggi yaitu kelas 4 sampai kelas 6 yakni sebanyak 61 subjek, siswa laki-laki berjumlah 25 dan siswa perempuan berjumlah 36. Subjek penelitian mendapatkan perlakuan tes kebugaran jasmani dan kecerdasan linguistk.

Tes pertama pada penelitian ini yaitu melakukan tes kebugaran jasmani pada aspek daya tahan menggunakan beep test. Pada tes kebugaran jasmani ini siswa melakukan lari bolak balik dengan jarak 20 meter dengan mengikuti irama beep yang semakin lama semakin cepat iramanya, sehingga siswa tidak mampu mengikuti irama tersebut. Maka itu tingkat kebugaran jasmani siswa pada aspek daya tahannya.

Tes kedua pada penelitian ini yaitu melakukan tes pada kecerdasan linguistik atau keterampilan berbahasa siswa. Peneliti menggunakan tes berupa angket atau kuesioner untuk melihat kecerdasan linguistik siswa, yang didalamnya memuat aspek membaca, menyimak, menulis dan berbicara. Setelah melakukan tes pertama kebugaran jasmani dan tes kedua kecerdasan linguistik 


\section{Journal STAND: Sports and Development}

http://jurnal.unipasby.ac.id/index.php/stand/about/submissions jurnal.stand@unipasby.ac.id

selanjutnya peneliti dapat melihat hubungan antara tes kebugaran jasmani dengan kecerdasan linguistik siswa. Adapun hasil dan kategori dari tes kebugaran jasmani dan kecerdasan linguistik siswa SD Negeri 2 Cimanggu dapat dilihat pada tabel berikut ini.

Tabel 1. Hasil Tes Kebugaran Jasmani

\begin{tabular}{lccc}
\hline No. & Kategori & $\begin{array}{c}\text { Jumlah } \\
\text { Siswa }\end{array}$ & Persentase \\
\hline 1. & Luar Biasa & 0 & $0,0 \%$ \\
2. & Sangat Baik & 9 & $14,7 \%$ \\
& & & \\
3. & Baik & 15 & $24,7 \%$ \\
4. & Rata-rata & 17 & $27,8 \%$ \\
5. & Sedang & 7 & $11,5 \%$ \\
6. & Rendah & 7 & $11,5 \%$ \\
7. & Sangat & 6 & $9,8 \%$ \\
& Rendah & $\mathbf{6 1}$ & $\mathbf{1 0 0 \%}$ \\
\hline \multicolumn{2}{c}{ Jumlah } & & \\
\hline
\end{tabular}

Tabel 2. Hasil tes kecerdasan linguistik

\begin{tabular}{lccc}
\hline No. & Kategori & $\begin{array}{c}\text { Jumlah } \\
\text { siswa }\end{array}$ & Persentase \\
& & & \\
\hline 1. & Sangat Baik & 3 & $4,9 \%$ \\
2. & Baik & 26 & $42,6 \%$ \\
3. & Cukup & 27 & $44,3 \%$ \\
4. & Kurang & 5 & $8.2 \%$ \\
\hline \multicolumn{2}{l}{ Jumlah } & $\mathbf{6 1}$ & $\mathbf{1 0 0 \%}$ \\
\hline
\end{tabular}

Tabel 3. Hasil uji normalitas

\begin{tabular}{llr}
\hline & & \multicolumn{2}{c}{ Unstandardized } \\
Residual & \\
$\mathrm{N}$ & &, 0000000 \\
\hline Normal & Mean &, 54159960 \\
Parameters(a,b) & &, 119 \\
& Std. Deviation &, 091 \\
Most Extreme & Absolute &,- 119 \\
Differences & &, 927 \\
& Positive &, 356 \\
& Negative & \\
Kolmogorov-Smirnov Z & \\
Asymp. Sig. (2-tailed) & \\
\hline
\end{tabular}

Berdasarkan data tabel diatas dapat dilihat bahwa data tes kebugaran jasmani dan kecerdasan linguistik berdistribusi normal. Hal ini dibuktikan dengan Asymp. Sig. (2-tailed) merupakan hasil normalitas data yang dibandingan dengan $a=0,05(0,356>0,05)$. Nilai Asymp. Sig. (2-tailed) merupakan indikasi yang dibandingkan dengan $a=0,05$. Apabila nilai Asymp. Sig. (2-tailed) lebih kecil dari 0,05 maka data tidak berdistribusi normal sedangkan apabila nilai Asymp. Sig. (2-tailed) lebih besar dari 0,05 maka data tersebut berdistribusi normal.

Tabel 4. Uji linearitas

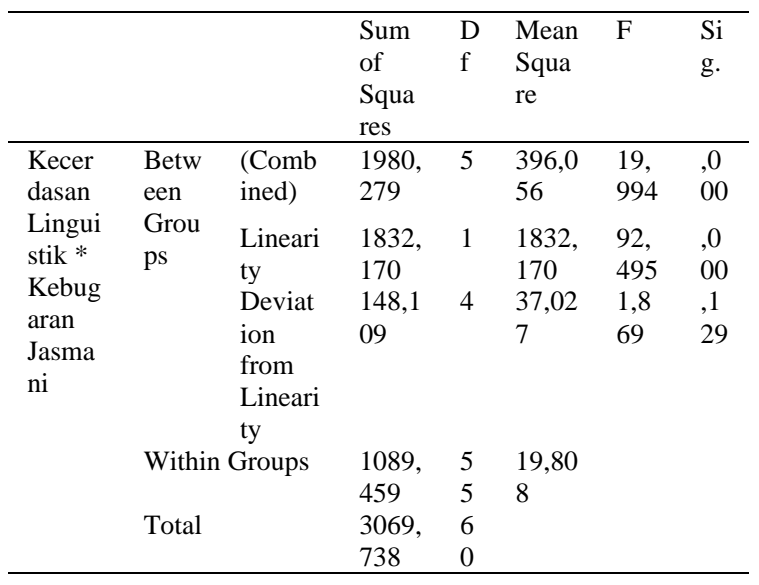

Berdasarkan data tabel diatas dapat dilihat hasil uji linearitas data tingkat kebugaran 


\section{Journal STAND: Sports and Development}

http://jurnal.unipasby.ac.id/index.php/stand/about/submissions jurnal.stand@unipasby.ac.id

jasmani dan kecerdesan linguistik memiliki hubungan linier atau searah hal ini dapat dilihat pada kolom Deviation from Linearity yaitu menghasilkan 0,129 yang artinya nilai signifikansi lebih besar dari 0,05. Maka dapat disimpulkan hasil uji linearitas data tes kebugaran jasmani dan kecerdasan linguistik dan nilai signifikansi $0,129>0,05$ yang artinya tes kebugaran jasmani dan kecerdasan linguistik memiliki hubungan yang searah.

Tabel 5. Hasil uji korelasional

\begin{tabular}{|c|c|c|c|}
\hline & & $\begin{array}{l}\text { Kebugaran } \\
\text { Jasmani }\end{array}$ & $\begin{array}{l}\text { Kecerdasan } \\
\text { Linguistik }\end{array}$ \\
\hline Kebugaran & Pearson & 1 & ,773(**) \\
\hline \multirow{3}{*}{ Jasmani } & Correlation & & \\
\hline & $\begin{array}{l}\text { Sig. (2- } \\
\text { tailed) }\end{array}$ & & , 000 \\
\hline & $\mathrm{N}$ & 61 & 61 \\
\hline \multirow{4}{*}{$\begin{array}{l}\text { Kecerdasan } \\
\text { Linguistik }\end{array}$} & Pearson &, $773(* *)$ & 1 \\
\hline & Correlation & & \\
\hline & $\begin{array}{l}\text { Sig. (2- } \\
\text { tailed) }\end{array}$ & , 000 & \\
\hline & $\mathrm{N}$ & 61 & 61 \\
\hline
\end{tabular}

Berdasarkan tabel diatas, terlihat koefisien korelasi pearson product moment kebugaran jasmani sebesar ,773(**). Artinya besar korelasi atau hubungan antara variabel tes kebugaran jasmani dan tes kecerdasan linguistik memiliki ialah 0,773 yang artinya kuat hubungan kedua variabel karena mendekati angka 1 .

Menurut Emzir (2018: 42) menjelaskan bahwa suatu koefisien korelasi memiliki angka desimal antara 0,00 dan $+1,00$, atau $-0,00$ dan 1,00; kedua variabel tersebut mempunyai hubungan. Dalam hasil analisis korelasi data tes kebugaran jasmani dengan kecerdasan linguistik menghasilkan koefisien korelasi
0,773 dikatakan kedua variabel tersebut memiliki hubungan kuat karena mendekati angka 1. Pada interpretasi nilai $r$ antara 0,600,80 memiliki hubungan kuat dalam artian hubungan antara kebugaran jasmani dengan kecerdasan linguistik siswa pada kelas tinggi SD Negeri 2 Cimanggu memiliki hubungan kuat dan searah yang artinya apabila kebugaran jasmani meningkat maka kecerdasan linguistik pun meningkat begitupun sebaliknya.

\section{KESIMPULAN}

Berdasarkan hasil penelitian dapat disimpulkan bahwa:

a. Tingkat kebugaran jasmani pada aspek daya tahan menggunakan beep test siswa kelas tinggi SD Negeri 2 Cimanggu siswa yang termasuk kategori Luar biasa (0 Siswa), Sangat baik (9 Siswa), Baik (15 Siswa), Rata-rata (17 Siswa), Sedang (7 Siswa), Rendah (7 Siswa), Sangat rendah (6 Siswa). Dengan demikian siswa dan guru memiliki gambaran umum dari tingkat kebugaran jasmani siswanya dan lebih berperan dalam menjaga tingkat kebugaran siswa.

b. Kecerdasan linguistik siswa menggunakan kuesioner yang meliputi aspek keterampilan membaca, keterampilan menulis, kegiatan menyimak dan keterampilan berbahasa siswa SD Negeri 2 Cimanggu yang termasuk kategori sangat baik (3 Siswa), baik (26 Siswa), cukup (27 Siswa) dan 
http://jurnal.unipasby.ac.id/index.php/stand/about/submissions jurnal.stand@unipasby.ac.id

kurang (5 Siswa). Dengan demikian guru memiliki gambaran umum dari kecerdasan linguistik siswanya.

c. Terdapat hubungan searah antara tingkat kebugaran jasmani dengan kecerdasan linguistik siswa dengan koefisien korelasi 0,773 menggunakan analisis bivariat product moment. Nilai r-hitung lebih besar dari nilai r-tabel, r-hitung didapat 0,773 dan nilai r-tabel 0,212 dengan $\mathrm{N}=61$. Maka r-hitung $(0,773)>$ r-tabel $(0,212)$ hal ini terdapat hubungan dengan kategori kuat antara variabel $\mathrm{X}$ tingkat kebugaran jasmani dengan variabel $\mathrm{Y}$ kecerdasan linguistik siswa. Hal ini dibuktikan oleh siswa yang mendapatkan hasil tes kebugaran jasmani baik maka mendapatkan hasil baik pula dari tes kecerdasan linguistik, begitupun sebaliknya

\section{REFERENSI}

Blaydes, Jean. 2001 Case for Daily Quality Physical Education. Data From the Early Childhood Longitudinal Study. Am J Publict Health, Vol. 82, No. 4.

Carisson dkk 2008. Physical Education and Academic Achievement in Elementary School: Data From the Early Childhood Longitudinal Study. Am J Publict Health, Vol. 98, No. 4.

Emzir, 2018. Metodologi Penelitian Pendidikan Kuantitatif dan Kualitatif. Jakarta: RajaGrafindo Perseda

Gardner, Howard. 2003. Kecerdasan Majemuk: Teori dalam Praktek. (Alih
Bahasa: Drs Alexander Sindoro). Batam Center: Penerbit Interaksara

Nur, Lutfi 2016. Pendidikan Jasmani dan Olahraha. Bandung: Rizqi Press

Podulka dkk 2006. Effect of Physical Education and Activity Levels on Academic Achievement in Childern. Med. Sci. Sport Exerc., Vol. 38, pp. 1515-1519.

Rahmawati, Karina. 2016. Faktor-Faktor Yang Mempengaruhi Kecerdasan Linguistik. Jurnal Pendidikan Guru Sekolah Dasar Edisi 3, Tahun ke 5 2016.

Sukardi, 2008. Metodologi Penelitian Pendidikan Kompetensi dan Praktiknya. Jakarta: Bumi Aksara

Tarigan, Beltasar. 2012. Optimalisasi Pendidikan Jasmani dan Olahraga Berlandaskan Ilmu Faal Olahraga. Bandung: FPOK UPI

Umaroh. 2013. Upaya Meningkatkan Kecerdasan Bahasa Melalui Model Cooperative Learning Pada Siswa Kelompok B di RA Muslimat NU Desa Kandang Kecamatan Comal Kabupaten Pemalang. Indonesian Journal of EarlyChildhood Education Studies. (1) 2013 